Oliva, C. A., Granja, A. D., Bridi, M. E., Soliman-Junior, J., Ayo-Adejuyigbe, M., and Tzortzopoulos, P. (2021). "Strengthening Target Value Design Benefits in the Real Estate Market through Living Labs." Proc. $2^{\text {th }}$ Annual Conference of the International Group for Lean Construction (IGLC29), Oliva; C. A; Granja; A. D.; Bridi, M. E.; Soliman-Junior, J.; Ayo-Adejuyigbe; M.; Tzortzopoulos; P. Lima, Peru, pp. 634-643, doi.org/10.24928/2021/0202, online at iglc.net.

\title{
STRENGTHENING TARGET VALUE DESIGN BENEFITS IN REAL ESTATE MARKET THROUGH LIVING LABS
}

\author{
Carolina A. Oliva ${ }^{1}$, Ariovaldo D. Granja ${ }^{2}$, Marcelle E. Bridi ${ }^{3}$, João Soliman- \\ Junior $^{4}$, Moralake Ayo-Adejuyigbe ${ }^{5}$, and Patricia Tzortzopoulos ${ }^{6}$
}

\begin{abstract}
The Target Value Design (TVD) is a collaborative process where value drives the design process to achieve the client's expectations while maintaining the costs and schedule under control. Its application has been successful ing several construction projects, especially in the healthcare context. Applying TVD to the real estate context, however, can be challenging. This paper aims to identify links between TDV and the Living Lab (LL) concept which may potentially help overcome these challenges. LLs are usercentred initiatives that focus on developing innovative solutions through cocreation and collaboration among stakeholders in a real-life context. A review on existing literature was performed to identify how a LL approach can strength TVD in a real state context. The results present opportunities to synergize TVD and LL for a beneficial result.
\end{abstract}

\section{KEYWORDS}

Target Value Design, living labs, innovation, real estate.

\section{INTRODUCTION}

Target Value Design (TVD) is an adaption of Target Costing (TC) for the delivery of projects in the construction industry (Ballard, 2011; Macomber et al, 2007; Zimina et al. 2012) and emerged from Toyota's TC system to manage the organization's profit margins (Kato, 1993; Ansari et al., 1997; Cooper and Slagmulder, 1997). It is a proactive cost management approach, encouraging collaboration among stakeholders and positioning costs and users' added value as a trigger to the design process (Ballard and Reiser, 2004; Macomber and Barberio, 2007; Ballard, 2011). The design teams must develop de product collaboratively, to achieve (or exceed) the client's expectations but keeping the

1 Post-Doctoral Researcher, University of Campinas, Brazil, carol_oliva@yahoo.com.br, orcid.org/0000-0003-2079-5472

2 Associate Professor, Laboratory for Construction Management Research (LAGERCON), University of Campinas, Brazil, adgranja@m.unicamp.br, orcid.org/0000-0002-2964-5609

3 PhD Student, Laboratory for Construction Management Research (LAGERCON), University of Campinas, Brazil, marcelle.bridi@gmail.com, orcid.org/0000-0003-4317-5938

4 Research Assistant, Innovative Design Lab (IDL), University of Huddersfield, UK, j.solimanjunior@hud.ac.uk, orcid.org/0000-0002-8089-8628

5 PhD Student, Innovative Design Lab (IDL), University of Huddersfield, UK, morolake.ayoadejuyigbe@hud.ac.uk

6 Professor, Innovative Design Lab (IDL), University of Huddersfield, UK, p.tzortzopoulos@hud.ac.uk, orcid.org/0000-0002-8740-6753 
project under the agreed budget (Zimina et al. 2012). Furthermore, it is strategically applied for innovation through cost reduction, involving the suppliers with the design team in order to seek for new design solutions while maintaining quality and other value generation features (Miron et al. 2015).

Evidence shows that TVD has been successfully applied, specially to healthcare projects (Ballard and Reiser 2004; Macomber and Barberio 2007; Rybkowski et al. 2011; Denerolle 2013; Do et al. 2014). Some examples in other contexts are reported in the literature. Russel-Smith et al. (2014) discussed the possibility of a Sustainable Target Value Design, aiming to reduce the life cycle impacts, setting targets for environmental indicators tools to evaluate the results and use TVD in green buildings design Additional research on TVD included classroom's layout improvements, using TVD to facilitate the decision-making process (Sahadevan and Varghese, 2019), and simulation games to engage stakeholders in Nigeria's real estate context (Musa et al. 2019).

However, to date, TVD application to the real estate context has been insufficiently explored, and there are limited practical applications in this environment (Oliva, 2014, Oliva and Granja 2015; Neto et al. 2016; Oliva et al. 2016; Neto et al. 2018). The real estate context poses some challenges for collaborative approaches such as TVD (Oliva, 2019). The real estate sector usually applies highly fragmented design processes (Melo and Granja, 2017; Oliva, 2019). Also, adversarial and opportunistic relationships between stakeholders exist, where individual (hidden) agendas overlap the collective interests. Successful reported TVD cases in such competitive and hostile environments in construction are still lacking, such as in real estate markets and the opportunity for strengthening TVD for adoption in this context was already previously discussed (Oliva et al; 2016). Furthermore, some of the key challenges for applying TVD in real estate in Brazil were identified: (a) fierce competition through similar products offers; (b) "long time to market", which means loss of business opportunities; (c) difficulties in capturing values attributes of potential customers and (d) product price is externally defined (Oliva and Granja (2019).

To overcome those contextual challenges, it is necessary to find innovative approaches and tools to strengthen and intensify communication, collaboration (Oliva, 2019), and shared understanding (Koskela et al., 2016) between the stakeholders. In this sense, TVD could potentially benefit from Living Labs (LL), which seeks innovative solutions produced in a real-life context, collaboratively and in co-creation with users. LLs are defined as "user-centric innovation milieu built on every-day practice and research, with an approach that facilitates user influence in open and distributed innovation processes engaging all relevant partners in real-life contexts, aiming to create sustainable values" (Bergvall- Kareborn et al. 2009, p. 3).

The conceptual roots of TVD assume collaborative relationships between stakeholders (i.e., architects, engineers, contractors, designers, suppliers, customers). The approaches related to TVD, such as Integrated Project Delivery (IPD) and Building Information Modelling (BIM), are relevant and can work as catalysts to promote collaboration. The authors put forward the proposition that higher levels of stakeholder engagement and shared understanding could be achieved by the joint application of TVD and LLs. Hence, the paper focuses on identifying possible synergies of innovative approaches such as the LL with TVD. Therefore, the paper discusses the potential of using LLs as an innovative approach to strengthen the TVD benefits achieved in e.g., healthcare projects, in TVD adoption in the real estate market context. 


\section{LIVING LABS}

The LLs are an innovation methodology that allows collaborative learning between users, researchers and producers in real-life experimentation. Users' needs are at the core of the LL process. It emerged in the early 1990s, exploring city neighbourhoods as a potential learning environment for students to engage in real-world problem solving (Geenhuizen, 2018). Nowadays, LLs initiatives can be either real-life experiments or arenas where participants collaborate to develop and test innovative solutions applying multiple approaches (ENOLL, 2021).

Through LLs, project participants engage collaboratively and share knowledge towards an innovation (Eriksson et al., 2005). The significant role of LL is to involve the key players in the development of an innovation, involving stakeholders and users required to coordinate the product and services under development (Almirall and Wareham, 2011). LL seeks to understand the techniques leading to ongoing changes through product innovation to support users' needs (Liedtke et al., 2012).

The creative process of involving humans in innovation is essential (Eriksson et al., 2005). To do so, LLs adopt a co-design and collaborative system that engages users and professionals to work together for a unique product by learning and creating a product in which users are key participants on the co-creation process (Almirall and Wareham, 2012; Eriksson et al., 2005; Leminen, 2015; Liedtke et al., 2012; Skiba et al., 2015).

Early users' involvement and understanding their requirements is a vital feature in LLs. The co-creation aspect is another pivotal learning aspect of the LLs approach. It should embrace problem-definition and problem-solving through improvisation and experimentation, testing solutions more dynamically. The co-creation aspect's learning process takes multiple approaches, such as seeking a product's improvement, defining future needs and observing behaviours (Geenhuizen, 2018).

This process requires developing tools for proper feedback collection, balancing different players` goals during the process, bridging gaps between users' needs and product functionalities, solving conflicts and dealing with a diverse teamwork, and at same time recognizing shared goals and values (Skiba et al., 2015; Geenhuizen, 2018).

LLs consider value from all stakeholders, under a user-driven approach and projecting the user as co-designer and producer (Leminen et al., 2012). The above briefly exposes that the core idea behind LLs initiatives is to include the users in a value-creation process (Angelini et al, 2016). This places LL as closely aligned with TVD, as they are both targeting to fulfil users' expectations by developing shared understanding between stakeholders (Koskela et al., 2016).

\section{RESEARCH METHOD}

This paper used the Literature Review as a methodological approach. Literature reviews can identify gaps in a particular theme, discuss a defined agenda or develop new theory, provide a theoretical basis to achieve new conceptual models, or map the literature on specific pieces over time (Snyder 2019).

There are different literature review approaches, according to Snyder (2019), such as a systematic review, integrative review and semi-systematic review. In this paper, the integrative review was the method adopted. This study seeks to access and synthesize literature to enable new theory or frameworks to emerge. This method is suitable to the I research aim, as it proposes new approaches to strengthen TVD in the real estate context. 
Review papers examine a particular research question by describing and synthesizing the appropriate literature using a theoretical method to provide readers with an understanding of recent research areas (Palmatier et al., 2018).

In the present research, three major themes were explored: (i)Target Value Design origins and context applications - in order to establish the main concepts of TVD and its state of art so far, successful applications contexts (19 articles); (ii) Target Value Design in Real Estate context - research and challenges for adoption - with the objective to explore the context of interest, this stage searched the literature for previous papers that explored TVD and real estate - which has proven to be scarce (6 articles); (iii) Living Labs - to extend the knowledge about its concepts and potentialities to strengthening TVD for a real estate adoption, and address its main challenges for adoption (22 articles).

\section{RESULTS AND DISCUSSION}

\section{THE LL APPROACH TO STRENGTHENING THE TVD}

When focusing attention on the real estate market, some challenges exist for a full-fledge TVD implementation, especially those concerning some externalities that are inherent of this context (Oliva et al., 2019; Oliva 2019). Our research suggests some LL concepts can be seen to help address some of the TVD issues observed in the real estate context, especially those related to collaboration, shared understanding and value alignment, as shown in Table 1. 
Table 1: Real estate key challenges and LLs propositions (The authors)

\begin{tabular}{c} 
Real estate key challenges \\
(Oliva et al., 2019; Oliva 2019): \\
\hline Fierce competition through similar products \\
offers \\
In the real estate market, various similar \\
products are offered by several construction \\
companies, so a potential customer must \\
choose between all those products, the one that \\
can deliver more value for the same price, in his \\
perspective.
\end{tabular}

"Long time to market", which means loss of business opportunities"

("Time to Market") - the product development process is too long. It is a fragmented process with low collaboration and a waste of time with a redesign and reworks. It can result in a loss of

business opportunities, as a competitor launches a similar product first.

\section{Difficulties in capturing values attributes of potential customers}

The companies often achieve obstacles in understanding and sharing the future user's value perspective with the design teams and incorporate it into product development. Usually, only post-occupancy evaluations are performed and not always provides feedback.

\section{Product price is externally defined}

In the TVD original context, the client establishes the team's target budgeting. In the real estate, the external market will determine

the average price. The profit margins are defined, so the left value is the cost target. This practice often results in confiscated value from the final user.

\section{Fierce competition through similar products offers}

In the real estate market, various similar products are offered by several construction companies, so a potential customer must choose between all those products, the one that can deliver more value for the same price, in his perspective.
LL propositions that can strengthen TVD adoption in the real estate context

Improving shared motivation for collaboration through LLs is essential and can help stakeholders overcome fierce competition when LL resources are made available to them (Veeckman et al., 2013). With improved co-creation innovations through LL, there is a tendency to have risk lowered, thereby increasing customer satisfaction and providing a competitive solution (Defillippi \&

Roser, 2014). Therefore, LL plays a mediating and facilitating role that allows for a participatory governance through shared value that ultimately integrates the interest of key participants to enhance a citizen-centered solution rather than a perceived competitor, making competition fierce (Angelini et al. 2016). Research and development can help efficiently, competitively, and socially drive products and services to an acceptable level that significantly reduces resources consumption. (Geibler et al., 2014).

LL can help in both practical and organizational implementation of innovations that can help manage the adoption of new ways of doing business by implementing innovation models that can foster time management (Schuurman \& Tõnurist, 2015). LL intervention can leverage the differences between research and market delivery in a fundamental and complicated structure (Claude et

al., 2017). Customers' involvement in the whole innovation process improves marketing strategy, thereby allowing for a trial period to customers before purchasing, which convinces them of product usefulness. There is a further development stage to commercialization with customer engagement (Zimmerling et al., 2017). The collaboration with users at the early innovation stage serves as a risk management helpful tool to obligatory companies in overcoming future obstacles.

Adopting a mixed set of $L L$ tools to discover new opportunities will help overcome the difficulty in capturing futuristic customers (Veeckman et al., 2013). Collaborative engagement of key participants in the natural environment is essential for developing attributes necessary for value capturing through the adoption of LL (Hossain et al., 2019). Exploring future needs and validating internal views is required at the initial stages with user's collaboration. And at a later stage, market success is increased through users' collaborative effort (Zimmerling et al., 2017).

From the previous perspectives, where we address the usercentered process of the LLs and with users and stakeholders working collaboratively, this may suggest opportunity to maintain the value perspective as a trigger to the design process, managing external influences, but this point still needs further exploration.

Improving shared motivation for collaboration through LLs is essential and can help stakeholders overcome fierce competition when LL resources are made available to them (Veeckman et al., 2013). With improved co-creation innovations through LL, there is a tendency to have risk lowered, thereby increasing customer satisfaction and providing a competitive solution (Defillippi \&

Roser, 2014). Therefore, LL plays a mediating and facilitating role that allows for a participatory governance through shared value that ultimately integrates the interest of key participants to enhance a citizen-centered solution rather than a perceived competitor, making competition fierce (Angelini et al. 2016).

Research and development can help efficiently, competitively, and socially drive products and services to an acceptable level that reduces resources consumption (Geibler et al., 2014). 
Considering the synergies identified in Table 1, LLs appear to be a promising way of strengthen TVD adoption in the real estate context, while overlapping some of the main challenges found in such context. Also, because of the commonalities between LL and TVD, it was possible to identify some synergies between the approaches, as highlighted in Table 2:

Table 2: Similarities between LLs and TVD (The authors)

\begin{tabular}{cc}
\hline TVD features (Macomber \& Barberio, & LL features (Eriksson et al., 2005; Liedtke et \\
2007; Zimina et al., 2012) & al., 2012; Skiba et al., 2015)
\end{tabular}

Collaborative decision-making by all project participants.

\section{Engagement with the client for establishing target value and throughout the design process for the continuous revealing of clients' needs \\ Several representatives' input to include relevant specialists and stakeholders committed to communicating and sharing design ideas. \\ Paying attention to the value established by the customer}

$\mathrm{LL}$ allows for collaborative learning between all stakeholders (Van Geenhuizen, 2019). There are also participatory processes enhanced by social innovation (Keyson et al., 2017)

\section{Continuous coincides with a process of demand creation situated in use contexts or potential markets that confront real adoption barriers.}

\section{Partners bringing their knowledge and know-how into the design team.}

Users as co-creators of value and innovations

Although the LL approach can enhance some principles from TVD (Table 1), its potential focuses on a catalyst more than a tool, whereas this approach may help to overcome some key challenges for the adoption of TVD in the context of the real estate market with units for sale. The LL focuses on user-centred value, collaboration, vital stakeholder's engagement (and is a broader approach), TVD is a more direct and specific approach, and the challenges inherit from the real estate market context could benefit from its adoption. It is also possible to assume that TVD can be suitable to support further systematic and value-oriented process on LLs, since value generation is not always explicit in LLs, but further research is needed to deepen those synergies.

In Table 2, we highlight some synergies between LLs and TVD, specially concerning the user involvement, value generation and collaboration between stakeholders. As the TVD basis is to put user value as a trigger to the product development process, under continuous collaboration among stakeholders, the LL approach has a similar proposal, whereas users' values and needs are un the cente, also seeking early involvement.

\section{CONCLUSIONS}

The TVD application in the real estate context can represent some obstacles. It encounters a very adversarial relationship between stakeholders, individual agendas, and very different levels of interest and influence in a determined product that can overlap the project's value perspective. Considering the LL as a broader user-centred approach towards co-creation, a TVD adoption within a LL perspective could facilitate overcome the obstacles presented in Table 1, with the early user and stakeholders' involvement in the process, shortening and adding value to solution, therefore strengthening TVD in this particular environment. It features collaboration, shared understanding, stakeholder's 
engagement and co-creation, especially in the highlighted TVD concepts related to collaboration, value perspective, co-location and communication. Also, artefacts can help operationalize the so-called boundary objects to enable and improve the so-called boundary objects, to enable and improve the relations between the actors involved in the product development process.

Future research could address a pilot testing a TVD adoption within a LL as an innovative approach to achieve and improve shared understanding, stakeholder's engagement and communication, overlap obstacles to a TVD adoption, and could validate and base further development of the conceptual analysis of this paper. Even though a fullfledge implementation can be challenging, a partial adoption could benefit the market's product offer, raising the value perspective for stakeholders overall.

\section{REFERENCES}

Almirall, E., and Wareham, J. (2011). "Living Labs: Arbiters of midand ground-level innovation". Technology Analysis and Strategic Management, 23(1), 87-102. https://doi.org/10.1080/09537325.2011.537110.

Alves, T. C. L., Lichtig, W., and Rybkowski, Z. K. (2017). "Implementing Target Value Design: Tools and Techniques to Manage the Process." 10(3), 18-29. doi.org/10.1177/1937586717690865.

Ansari, S., Bell, J., the CAM-I Target Costing Group, 1997, Target costing - the next frontier in strategic cost management, Chicago, Irwin.

Angelini, L., Carrino, S., Khaled, O. A., Riva-mossman, S., \& Mugellini, E. (2016). Senior Living Lab: An Ecological Approach to Foster Social Innovation in an Ageing Society. 1-19. doi.org/10.3390/fi8040050.

Ballard, G. (2011). "Target Value Design: Current Benchmark". Lean Construction Journal, 79-84.

Ballard, G., and Reiser, P. (2004). "The St. Olaf College Fieldhouse project: a case study in designing to target cost". Proceedings, International Group for Lean Construction. Dinamarca: [s.n.].

Bresnen, M. (2010). "Keeping it real? Constituting partnering through boundary objects". Construction Management and Economics, 28:6, 615-628, doi.org/10.1080/01446191003587711.

Claude, S., Ginestet, S., Bonhomme, M., Moulène, N., \& Escadeillas, G. (2017). The Living Lab methodology for complex environments: Insights from the thermal refurbishment of a historical district in the city of Cahors, France. Energy Research \& Social Science, 32, 121-130. doi.org/10.1016/j.erss.2017.01.018.

Cooper, R. and Slagmulder, R., 1997. Target costing and value engineering, Portland, Productivity Press.Defillippi, R., \& Roser, T. (2014). Aligning the co-creation project portfolio with company strategy. 42(1), 30-36. doi.org/10.1108/SL-10-2013-0075.

Denerolle, S. (2013). "The application of Target Value Design to the design phase of 3 hospital projects". Project Production Systems Laboratory - University of California. Berkeley.

Do, D., Chen, C., Ballard, G., and Tommelein, I. (2014). "Target Value Design as a Method for Controlling Project Cost Overruns". Proceedings IGLC-22, June 2014. Oslo, Noruega: [s.n.]. p. 171-181.

Eriksson, M., Niitamo, V. P., and Kulkki, S. (2005). "State-of-the-art in utilizing Living Labs approach to user-centric ICT innovation-a European approach". Lulea: Center for Distance-spanning Technology. Lulea University of Technology Sweden: Lulea. 
Lulea: Center for Distance-Spanning Technology., 1(13), 1-13. doi.org/10.1145/2072069.2072092.

Geibler, J. Von, Erdmann, L., Liedtke, C., Rohn, H., Stabe, M., Berner, S., Leismann, K., Schnalzer, K., \& Kennedy, K. (2014). Exploring the Potential of a German Living Lab Research Infrastructure for the Development of Low Resource Products and Services. 575-598. doi.org/10.3390/resources3030575.

Hossain, M., Leminen, S., \& Westerlund, M. (2019). A systematic review of living lab literature. Journal of Cleaner Production, 213, 976-988. doi.org/10.1016/j.jclepro.2018.12.257.

Kato, Y., 1993, 'Target costing support systems: lessons from leading Japanese companies', Management Accounting Research 4, 33-47.

Keyson, D. V., Guerra-Santin, O., and Lockton, D. (Eds.) (2017). "Living labs: design and assessment of sustainable living." Springer. doi.org/10.1007/978-3-319-33527-8.

Koskela, L., Pikas, E., Gomes, D., Biotto, C., Talebi, S., Rahim, N., and Tzortzopoulos, P. (2016). "Towards shared understanding on common ground, boundary objects and other related concepts." In: Proc. 24th Ann. Conf. of the Int'l. Group for Lean Construction, Boston, MA, USA, sect.1 pp. 63-72.

Lee, H. W., Ballard, G., and Tommelein, I. "Developing a Target Value Design Protocol for Commercial Energy Retrofits - Part 1". Construction Research Congress ASCE. West Lafayette, Indiana: [s.n.]. 2012. p. 1710-1719.

Leminen, S. (2015). "What Are Living Labs?" Technology Innovation Management Review, 5(9), 29-35. doi.org/10.22215/timreview928.

Leminen, S., Westerlund, M., and Nyström, A. G. (2012). Living Labs as OpenInnovation Networks. Technology Innovation Management Review, 2(9), 6-11. doi.org/10.22215/timreview602.

Liedtke, C., Jolanta Welfens, M., Rohn, H., and Nordmann, J. (2012). "LIVING LAB: User-driven innovation for sustainability". International Journal of Sustainability in Higher Education, 13(2), 106-118. doi.org/10.1108/14676371211211809.

Newcombe, R. (2003). "From client to project stakeholders: a stakeholder mapping approach". Construction Management and Economics (December 2003) 21, 841-848.

Macomber, H., and Barberio, J. (2007). "Target-Value Design: Nine Foundational Practices for Delivering Surprising Client Value". TVD Foundational Practices. 2-4.

Melo, R. S. S., Do, D., Tillmman, P., Ballard, G., and Granja, A.D. (2015). "Target value design in the public sector: evidence from a hospital project in San Francisco, CA". Architectural, Engineering and Design Management, Nov 2015. 1-14.

Miron, L.I.G., Kaushik, A., and Koskela, L. (2015). "Target Value Design: The Challenge of Value Generation". In: Proc. 23rd Ann. Conf. of the Int'1. Group for Lean Construction. Perth, Australia, July 29-31, pp. 815-825.

Musa, M., Pasquire, C., and Hurst, A. (2019). "Using TVD Simulation to Improve Collaboration". Proc. 27th Annual Conference of the International Group for Lean Construction (IGLC). Dublin, Ireland: [s.n.]. 2019. p. 503-514.

Neto, H. M., Costa, D. B., and Thomas, L. (2016). "Target value design approach for real estate development”. In: Proc. 24th Ann. Conf. of the Int'1. Group for Lean Construction, Boston, MA, USA, sect.3 pp. 63-72.

Neto, H. M., Costa, D. B., and Ravazzano, T. C. (2018). "Recommendations for Target Value Design implementation for real estate development in Brazil". 2007. doi.org/10.1080/17452007.2018.1509054. 
Oliva, C. (2014). "Proposal for Target Value Design integration into Design Process Management in Civil Construction Projects" (translated). Master's Thesis. The School of Civil Engineering, Architecture and Urban Design - UNICAMP - the State University of Campinas, Brazil.

Oliva, C., and Granja, A. D. (2015). "Proposal for target value design adoption in the design management in real estate projects" (translated). Ambiente Construído. Porto Alegre, 15(4), 131-147.

Oliva, C., Granja, A. D., Ballard, G., and Melo, R. (2016). “Assessing suitability of target value design adoption for real estate developers in Brazil". In 24th Annual Conference of the International Group for Lean Construction. Boston, USA, 2016.

Oliva, C. (2019). "Target Value Design in the Real Estate Market with Units for Selling: Model and Guidelines for Implementation" (translated). PhD Thesis (in Portuguese). he School of Civil Engineering, Architecture and Urban Design - UNICAMP - the State University of Campinas, Brazil.

Onwuegbuzie, A. J., and Frels, R. (2016). "Methodology of the Literature Review. In: Seven Steps to a Comprehensive Literature Review: A Multimodal and Cultural Approach". Sage Publications, UK.

Palmatier, R. W., Houston, M. B., and Hulland, J. (2018). "Review articles: purpose, process, and structure". Journal of the Academy of Marketing Science (2018) 46:15. doi.org/10.1007/s11747-017-0563-4.

Russell-Smith, S. V., Lepech, M. D., Fruchter, R., and Littman, A. (2014). "Impact of progressive sustainable target value assessment on building". Building and Environment, November 2014. 52-60.

Rybkowski, Z. K., Munankami, M. B., Gottipati, U., and Lavy, S. (2011). "Towards an Understanding of Cost and Aesthetics: Impact of Cost Constraints on Aesthetic Ranking Following Target Value Design Exercises". 21st Annual Conference of the International Group for Lean Construction, 1-10.

Sahadevan, V., and Varghese, K. (2019). "AHP and CBA Application to Layout Design: A Case of Classroom Layout Assessment" In: Proc. 27th Annual Conference of the International. Group for Lean Construction (IGLC), Pasquire, C and Hamzeh FR (Ed). Dublin, Ireland, pp. 1333-1344. doi.org/10.24928/2019/0256.

Schuurman, D., \& Tõnurist, P. (2015). Innovation in the Public Sector: Exploring the Characteristics and Potential of Living Labs and Innovation Labs.

Silveira, S., and Alves, T. (2018). "Target Value Design Inspired Practices to Deliver Sustainable Buildings" (2018). Buildings ,8, 116. doi.org/10.3390/buildings8090116.

Skiba, N., Morel, L., Guidat, C., and Camargo, M. (2015). "How to emphasize the "living" part of Living Lab projects?" 2013 International Conference on Engineering, Technology and Innovation, ICE 2013 and IEEE International Technology Management Conference, ITMC 2013, 1-12. doi.org/10.1109/ITMC.2013.7352701.

Snyder, H. (2019). "Literature review as a research methodology: An overview and guidelines". Journal of Business Research, 104 (March), 333-339. doi.org/10.1016/j.jbusres.2019.07.039.

Van Geenhuizen, M. (2018). "A framework for the evaluation of living labs as boundary spanners in innovation". Environment and Planning C: Politics and Space, 36(7), 1280-1298. doi.org/10.1177/2399654417753623.

Van Geenhuizen, M. (2019). Applying an RRI filter in key learning on urban living labs' performance. Sustainability (Switzerland), 11(14). doi.org/10.3390/su11143833. 
Van Der Walt, J. S.,. Buitendag, A. A. K, Zaaiman, J. J., and Van Vuuren, J. J. C. (2009). "Community Living Lab as a Collaborative Innovation Environment". Issues in Informing Science and Information Technology, 6 (January), 421-436. doi.org/10.28945/1070.

Veeckman, C., Schuurman, D., Leminen, S., \& Westerlund, M. (2013). Linking Living Lab Characteristics and Their Outcomes: Towards a Conceptual Framework. December, 6-15.

Zimina, D., Ballard, G., and Pasquire, C. (2012). "Target value design: using collaboration and a lean approach to reduce construction cost Target value design". Construction Management and Economics, 30(5), 383-398. doi.org/10.1080/01446193.2012.676658.

Zimmerling, E., Purtik, H., \& Welpe, I. M. (2017). End-users as co-developers for novel green products and services e an exploratory case study analysis of the innovation process in incumbent firms. Journal of Cleaner Production, 162, S51-S58. doi.org/10.1016/j.jclepro.2016.05.160. 